\title{
Inquiry-Directed Organization of E-Portfolio Artifacts for Reflection
}

\author{
Shouhong Wang \\ University of Massachusetts Dartmouth, MA, USA
}

swang@umassd.edu

\begin{abstract}
The literature of learning objects has suggested that an explicit organizational structure of the repository of learning objects can be an informing layer between the user and the repository to support planned teaching and learning. This paper describes how domain knowledge can be used to develop organizational structures of learning objects to support designed teaching and learning. The theme of this study is the design of organizational structures of e-portfolios for reflection. The paper proposes a model of inquiry-directed organization of e-portfolio artifacts based on the paradigms and models of reflection. It presents a case study of implementation of this model.
\end{abstract}

Keywords: Learning object, organization of learning objects, e-portfolios, reflection, inquirydirected organization, design research.

\section{Introduction}

E-portfolio systems have been widely used in education institutions. E-portfolios are supposed to serve three purposes: assessment, showcase, and learning (Greenberg, 2004; Wall, Higgins, Miller, \& Packard, 2006). For assessment purposes, e-portfolios include rubrics-based documentations and assessment files. For showcase purposes, e-portfolios present artifacts of accomplishments to demonstrate career development. For learning purposes, e-portfolios can be useful for on-going learning and reflection. The current commercial or open source e-portfolio systems have been successfully used for assessment and showcase but have not been effectively applied to enhancing students' learning (Zhang, Olfman, \& Rectham, 2007). This is mainly because generic e-portfolio systems are more or less learning subject independent. On the other hand, useful learning portfolios must be accessed dynamically to meet a variety of needs in learning. Integrated reflection is an active learning process across the boundaries between courses, disciplines, or even fields to learn what the learner has experienced. This challenge raises a significant research question: how theories and practices of e-learning can be applied to e-portfolios for effective integrated reflection.

E-portfolio artifacts are learning objects. As discussed in the next section, the literature of learn-

Material published as part of this publication, either on-line or in print, is copyrighted by the Informing Science Institute. Permission to make digital or paper copy of part or all of these works for personal or classroom use is granted without fee provided that the copies are not made or distributed for profit or commercial advantage AND that copies 1) bear this notice in full and 2) give the full citation on the first page. It is permissible to abstract these works so long as credit is given. To copy in all other cases or to republish or to post on a server or to redistribute to lists requires specific permission and payment of a fee. Contact 0HPublisher@InformingScience.org to request redistribution permission. ing objects has suggested that an explicit organizational structure of the repository of learning objects can be an informing layer between the user and the repository to support planned teaching and learning. Accordingly, to make generic e-portfolio systems more useful for enhancing students' reflection, a layer between the user and the e-portfolio artifacts must be developed to facilitate students' integrated reflection. This paper 
describes how domain knowledge can be used to develop an organizational structure of e-portfolio artifacts to achieve this goal. It proposes a model of reflection-oriented organizational structure of e-portfolio artifacts. The ultimate objective of this study is to build on the theories and cumulative knowledge of learning objects for e-learning.

\section{Related Work on E-Portfolios as Learning Objects}

A portfolio is a systematic and purposeful collection of work and achievement documentation (Drier, 1997). E-portfolios are highly personalized, customizable, Web-based files that document learning portfolios and demonstrate individual and collaborative learning process (McCowan, Harper, \& Hauville, 2005). An e-portfolio system is a Web-based repository management system that stores students' learning documents under the name of artifacts, such as academic records, essays, project reports, assignments, assessments, and personal and professional development related contents. Students use e-portfolio systems to present artifacts, receive feedback from instructors and advisors, and communicate with each other.

There are many commercial, non-profit organizational, and open-source e-portfolio systems, such as Chalk \& Wire (2009), KEEP toolkit (KEEP, 2009), foliotek (2009), TaskStream (2009), and Open-Source Portfolio (OSP) (2005). While there are high variations of user interface design among these e-portfolio systems, the functionalities of competitive e-portfolio systems are about the same, including artifacts editing and uploading, commenting and assessing on student work, communicating and sharing, showcase generating, and administrative reporting.

E-portfolios are stored online and have great accessibility for the portfolio owners themselves, teachers, colleagues, and employers (Bruder, 1993; Bushweller, 1995; McCowan et al., 2005). Eportfolios are a mechanism for students and education institutions to demonstrate and improve their teaching/learning skills and to display competencies to the society (Ali, 2008; Lumsden, Garis, Reardon, Unger, \& Arkin, 2001). E-portfolio systems enable the administration at all levels to conduct comprehensive assessment of teaching and learning accomplishments (Barrett, 1994).

An e-portfolio artifact is a unit of digital resource that can be used to support learning and, thus, is a learning object (Wiley \& Edwards, 2002). Along with the proliferation of e-learning systems, learning objects become increasingly valuable, and, at the same time, the management of learning objects repository becomes complicated (Cohen \& Nycz, 2006; Collis \& Strijker, 2003; Singh Hawkins, \& Whymark, 2007). There have been metadata standards for learning objects, such as those proposed by Dublin Core (2009), IEEE LTSC (IEEE LTSC, 2009), and IMS Guide (IMS, 2006), that are similar to library catalogue systems. However, to effectively use learning objects to support teaching and learning for a specific field, additional techniques must be applied to manage the learning objects (Harman \& Koohang, 2005; Koohang, 2004; Mustaro \& Silveira, 2006; Namuth, Fritz, King, \& Boren, 2005; Sicilia \& Lytras, 2005; Smrz, 2004; Zouaq, Nkambou, \& Frasson, 2007).

In building on theories of learning objects, research (e.g., Snae \& Brueckner, 2007; Wang, 2008, 2009) has indicated that ontological structures of learning objects are indispensable in making effective access of learning objects to support teaching and learning processes. This suggests that an ontology-based intermediate layer as the interface between the user and the repository of learning objects can facilitate the proficient use of learning objects for planned teaching and learning. Clearly, the premise of the ontological approach is the availability of knowledge about the relationships between the learning objects.

In this research direction, the present study takes one step further by demonstrating how learning objects can be organized for designed teaching and learning based on domain knowledge. The example used in this study will be the construction of inquiry-directed organization of e-portfolio artifacts for reflection. 


\section{Reflection: Paradigms, Models, and Challenges for E-Portfolios}

Reflection is "an active, persistent, and careful consideration of belief or supported form of knowledge in the light of the grounds that support it and the further conclusions to which it tends" (Dewey, 1933). Reflection is crucial in active construction of knowledge based on the learner's prior experiences (Koohang, Riley, Smith, \& Schreurs, 2009). Reflection has been studied for a long time (Dewey, 1909, as cited in Fisher, 2001, p. 9; Fisher, 2001; Huitt, 1998; Paul, 1985). There have been many terms for phrasing reflection in the literature, such as reflective thinking, critical thinking, creative thinking, good thinking, deep thinking, and self-learning. Nevertheless, the taxonomy of reflection has not been made clear. Skeptically, as reflection is so complicated in general, any taxonomy is unlikely to be applicable to all disciplines.

Although the real reflection activities in the human brain remain by and large an enigma, descriptions of directed thinking routines (Ritchhart, 2002) for the reflection process can make reflection visible as well as teachable. Research (Perkins, Jay, \& Tishman, 1993a; 1993b; Varner \& Peck, 2003) has made connections between students' learning portfolios and reflection and has asserted that students' learning portfolios can have significant contributions to teaching and learning reflection.

Next, we discuss paradigms of reflection in the perspective of teaching and learning reflection through e-portfolios.

\section{Non-Discipline-Specific Reflection}

Along with the proliferation of e-portfolios, there have been discussions on non-disciplinespecific reflection through the use of e-portfolios (Annis \& Jones, 1995; Batterbee \& Dunham, 2004; Zubizarreta, 2004). Essentially, three major paradigms of non-discipline-specific reflection are discussed in the literature: career development, academic accomplishment, and extracurricular learning.

\section{Career development}

Career development reflection is the continuous thinking process on personal mission, career selection and career path, career change, and long-term goals. Career development reflection enables the individual to persistently review career-oriented plan and to assess personal strengths and weaknesses of skills, abilities, motivations, flexibility and adaptability, creativity and productivity, and personal dispositions on her/his own. Career development reflection is the mental preparation for the individual to establish and to sustain professional competence in the rapidly changing world.

\section{Academic accomplishment}

Academic accomplishment reflection enables students to plan academic success, to evaluate inclass learning, to develop creativity, and to recognize gaps between the existing knowledge and curricula competences. It presents evidence of students' academic progress over the time and engages students in ongoing self-assessment of lifelong learning. Students' academic portfolios are particularly important for academic accomplishment reflection.

\section{Extra-curricular learning}

Extra-curricular learning is based on the belief that the acquisition of knowledge and skills extends far beyond formal classroom education. Learning outside the classroom encompasses a wide range of learning scenarios. Extra-curricular learning reflection enables students to cele- 
brate broad life experiences, to develop social skills and responsibility, and to become selfmotivated lifelong learners.

\section{Discipline-Specific Reflection}

Although reflection emphasizes general thinking strategies and abilities across diverse situations, discipline-specific knowledge can guide reflection that is relevant to the particular discipline (Ericsson \& Smith, 1991). Reflective thinking on decision making process (Warnick \& Inch, 1994), organizational learning (Senge, 1990), and system's factors (Checkland, 1981) are examples of discipline-specific reflection in the behavioral science fields.

Clearly, the cut-lines between the reflection paradigms can never be sharp. Also, it is not the intention of this study to identify all types of reflection paradigms. The focal point of this discussion is to gain more understanding about the different modes of reflection and to investigate how we can teach reflection in the common paradigms.

\section{Models of Reflection}

As reflection involves complex cognitive aspects and has a variety of distinct paradigms, there have been countless models of reflection in the literature. Nevertheless, models of reflection can be classified into two categories: procedural model and dominant model.

\section{Procedural model}

Reflection is a thinking process more than simple memorization and comprehension and involves a variety of cognitive processes, such as summarization, identifying general principles, exploring various situations, reconciling options, and monitoring progress. There have been many procedural models that share common basic stages of reflection: experiencing, analyzing the situation and knowledge learned from the experiences, and internalizing the learning to generalize wisdom for the future. Kolb's (1984) structured reflection learning cycle model is a representative reflection procedural model. It asserts that reflection is an experiential learning cycle which has four stages: concrete experience, analysis of observations, generalization, and planning future action. Similarly, Boud, Keogh, and Walker (1985) describe three-stage activities in reflective learning: preparation, engagement, and processing. In the preparatory phase, the learner examines the situation. During the engagement, the learner reviews the experience received from the practice. Finally, a learner must consolidate the experience to apply it in new context. Gibbs' (1988) reflective cycle model is another popular reflection procedural model which we consider to be a variant version of these reflection procedural models.

\section{Dominant model}

Although reflection emphasizes general thinking strategies and abilities across diverse situations, the structured thinking model can guide sophisticated reflection (Ericsson \& Smith, 1991). Boud et al. (1985) suggest that structured reflection is the key to learning from experience. Aram and Noble (1999) argue that instructional models of learning and thinking are appropriate for reflection. Dunne and Martin (2006) maintain that, to teach and learn integrated reflection, we need structured instruments or guidelines for reflection, and the model is an important tool, if not the only one, that compels integrated reflection. While the ultimate models of reflection in great students' mind might not be available, there is little doubt that instructional models can provide guidelines for integrated reflection. We refer to instructional structured thinking models for teaching and learning integrated reflection as reflection dominant models. For instance, the SWOT (strength, weakness, opportunity, threat) analysis model can provide pertinent guidelines for students to conduct non-discipline-specific reflection. The decision making model (Simon, 1976) taught in social science fields can help students develop reflection dispositions of decision making. Students can apply this dominant model to any decisions across social science subjects 
and think about the decision making process as well as the important roles of data and information in decision making.

Clearly, teachers can use typical dominant models, or develop their own dominant models for teaching reflection.

\section{Reflection inquiry}

Posing questions to the student is an effective approach to teaching reflection (Guskin, 1994; Schon, 1983). A reflection model can have its questions, or reflection inquiries, for students to think about. A reflection inquiry can be very general. For instance, the SWOT dominant model can have generic reflection inquiries, such as: What is your strength in pursuing your career? What is your weakness in your major courses? Do you perceive any opportunity in extracurricular learning? A reflection inquiry can also be specific to address an individual student's work. For instance, the SWOT dominant model can have a reflection inquiry based on a specific situation, such as: What makes your success in the computer literacy courses?

In summary, reflection procedural models are general frameworks for teaching and learning reflection, reflection dominant models are tools or instruments for teaching and learning integrated reflection, and reflection inquiries are detailed instructions for teaching and learning reflection. Clearly, specific actualized reflection procedures, dominant models, and inquiries always depend upon the teacher's or the learner's own analysis of situations.

\section{Challenges for E-Portfolio Systems}

Reflection should be a habitual activity. The education community has no doubt that students' own learning portfolios provide supporting resource for reflection (Zubizarreta, 2004). Nevertheless, the e-portfolio community has not demonstrated how e-portfolios in the role of learning objects can be effectively used for teaching and learning integrated reflection. Specifically, organizational structures are still to be developed for e-portfolio systems to organize e-portfolio artifacts to support teaching and learning integrated reflection. To meet this challenge, we propose a model of inquiry-directed organization of e-portfolios for reflection. The objective of this model is to gain more understanding about the roles of e-portfolios as an effective tool for teaching and learning reflection.

\section{Designing Inquiry-Directed Organization of E-Portfolios}

\section{Model of Inquiry-Directed Organization of E-Portfolios}

As explained in the previous sections, reflection models and reflection inquiries are the instruments and instructions for teaching and learning reflection, and e-portfolios can be useful sources for reflection. Accordingly, association between reflection inquiries and e-portfolio artifacts becomes the central issue of application of e-portfolios for reflection. In this study, we propose two techniques to implement such association: inquiry structure and semantic metadata.

\section{Reflection inquiry structure}

A reflection model can involve many reflection inquiries, and a reflection inquiry can have many sub-inquiries. Reflection inquiry structure defines these hierarchical relationships. For example, a SWOT reflection model can have reflection inquiries on strength, weakness, opportunity, and threat. A reflection inquiry on strength can have specific inquiries on strength in verbal communication skills and in quantitative analysis abilities. A reflection inquiry structure could be either "standard" for all students or customized for an individual student. An e-portfolio artifact can be linked to the relevant reflection inquiries so that it is integrated into the inquiry structure. 
Inquiry-Directed E-Portfolios for Reflection

A reflection inquiry structure would allow the learner to better understand the overall reflection tasks. It also allows the learner to follow reflection instructions and review all relevant eportfolio artifacts in conducting reflection.

\section{Semantic metadata}

Semantic metadata are keywords that best categorize reflection inquiries. For instance, the reflection inquiry "What is your strength in your major courses?" can have keywords such as "SWOT", "academic accomplishment", "career development". These keywords are semantic metadata. An e-portfolio system can have a semantic metadata dictionary for all available reflection models and reflection inquiries. To associate an e-portfolio artifact with reflection inquiries, one assigns the artifact with relevant keywords.

Semantic metadata can be useful for a global search for relevant e-portfolio artifacts from the eportfolio repository for a particular reflection inquiry. Clearly, a dictionary of semantic metadata is generated based on specific knowledge of teaching reflection. From the viewpoint of organization of e-portfolios, the inquiry structure implements the inquiry-directed organization in a static way, while the semantic metadata do so in a dynamic way.

The above two techniques implement the association between e-portfolios and reflection models so that e-portfolio artifacts can be accessed in line with reflection inquiries. The model of inquiry-directed organization of e-portfolios for reflection is depicted in Figure 1.

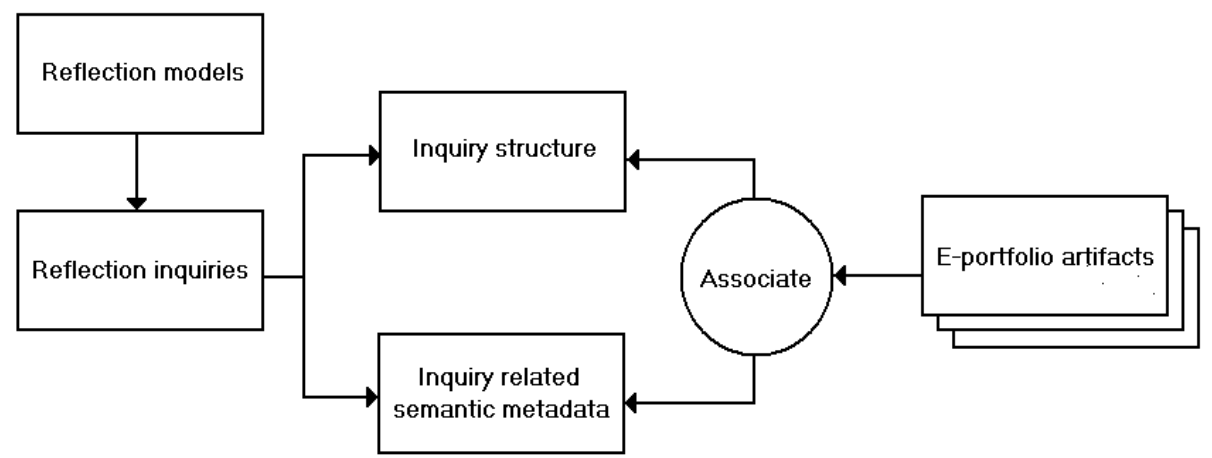

Figure 1: Model of Inquiry-Directed Organization of E-Portfolios.

\section{A Case Study of Designing Structures of E-Portfolios for Reflection}

To learn more about inquiry-directed structure of e-portfolios for integrated reflection, a project was conducted to investigate the feasibility of implementing the proposed model on an existing eportfolio system. We implemented the model on Chalk \& Wire ePortfolio2 (Chalk \& Wire, 2009). Chalk \& Wire ePortfolio2 is a pioneer e-portfolio system which has widely been used in Canada, the United States, and other countries.

We used the Chalk \& Wire ePortfolios2 platform to implement a prototype of extension shell of the system, called ReInq, for reflection through inquiry. Figure 2 shows the context of ReInq with relation to the types of e-portfolio artifacts (in Italic in Figure 2) of the Chalk \& Wire ePortfolios2 system. My Portfolios represents student's portfolios. Artifact Library contains all eportfolio artifacts in My Portfolios. Chalk \& Wire ePortfolio2 has Table of Content (TOC) and Assessments. These two special types of artifacts are able to connect or generate e-portfolio artifacts that could be related to reflection in the aspect of assessment. Note that the Chalk \& Wire 
ePortfolio2 system must link a TOC to a Rubric(s). Although Figure 2 does not include Rubric in order not to dilute our emphasis on the inquiry-directed model, one needs to create a rubric for a TOC to make Assessments.

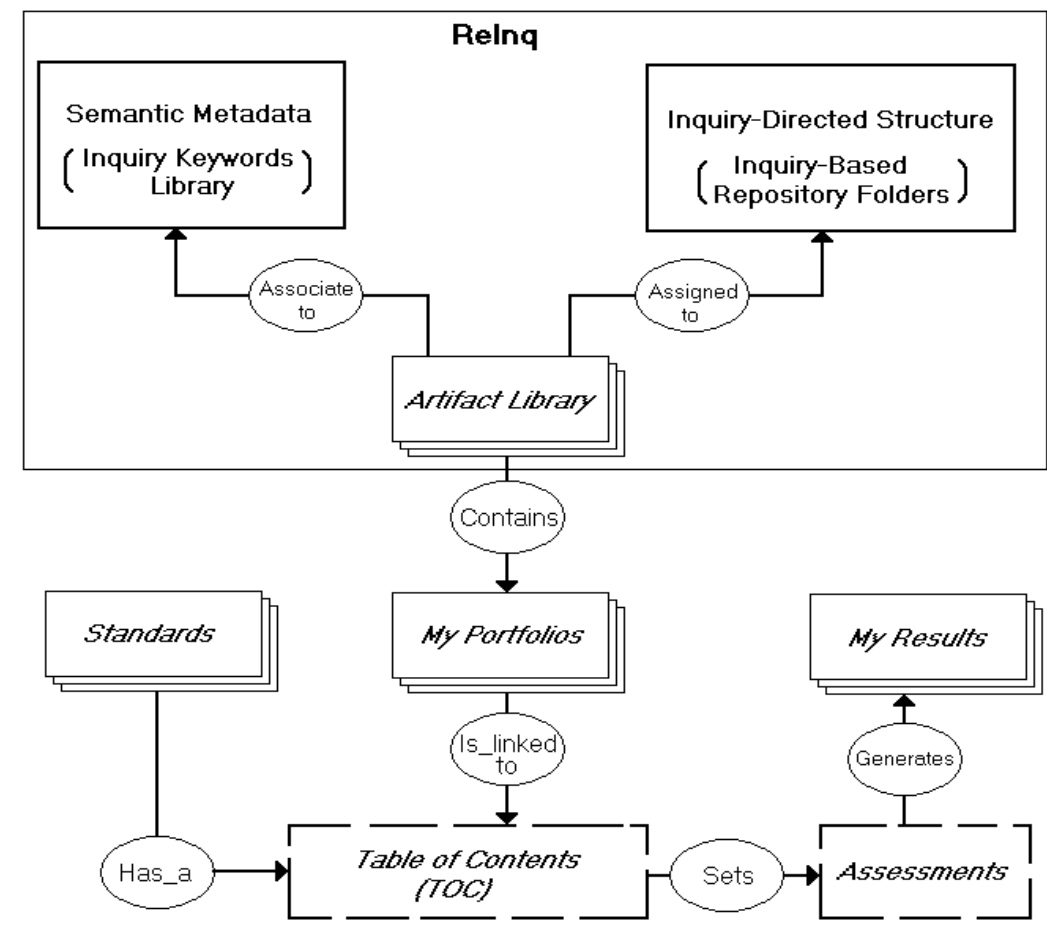

Figure 2: ReInq on Chalk \& Wire ePorfolios2 System.

Here, we present the features of ReInq. This is merely to demonstrate the design of inquirydirected organization of e-portfolio artifacts for teaching and learning integrated reflection, but not the design of reflection inquiries which is a topic independent of this study. The example in Figure 3 shows the inquiry-directed hierarchical structure of e-portfolio artifacts for reflection. The user (the teacher or the student) is able to view the reflection inquiry structures, locate a specific inquiry, and place a relevant artifact into the inquiry folder. An e-portfolio artifact can have multiple connections with many reflection inquiries. In the current form of ReInq which was based completely on the platform of Chalk \& Wire ePortfolio2 system, this was done through physical replication. The user is also able to edit and update the inquiry structure, as shown in Figure 4. Figure 5 shows the user interface for assignment of keywords to an artifact. By assigning keywords to an artifact, the user actually defines semantic metadata for the artifact. The semantic metadata dictionary of ReInq was implemented in an independent e-portfolio artifact. Figure 6 shows the use of semantic metadata for searching artifacts for reflection. When the student performs reflection by addressing an inquiry, she is able to find all relevant e-portfolio artifacts in the corresponding folder. Once she completed reflection, the TOC sets Assessments for the teacher to generate My Results as an assessment outcome. 


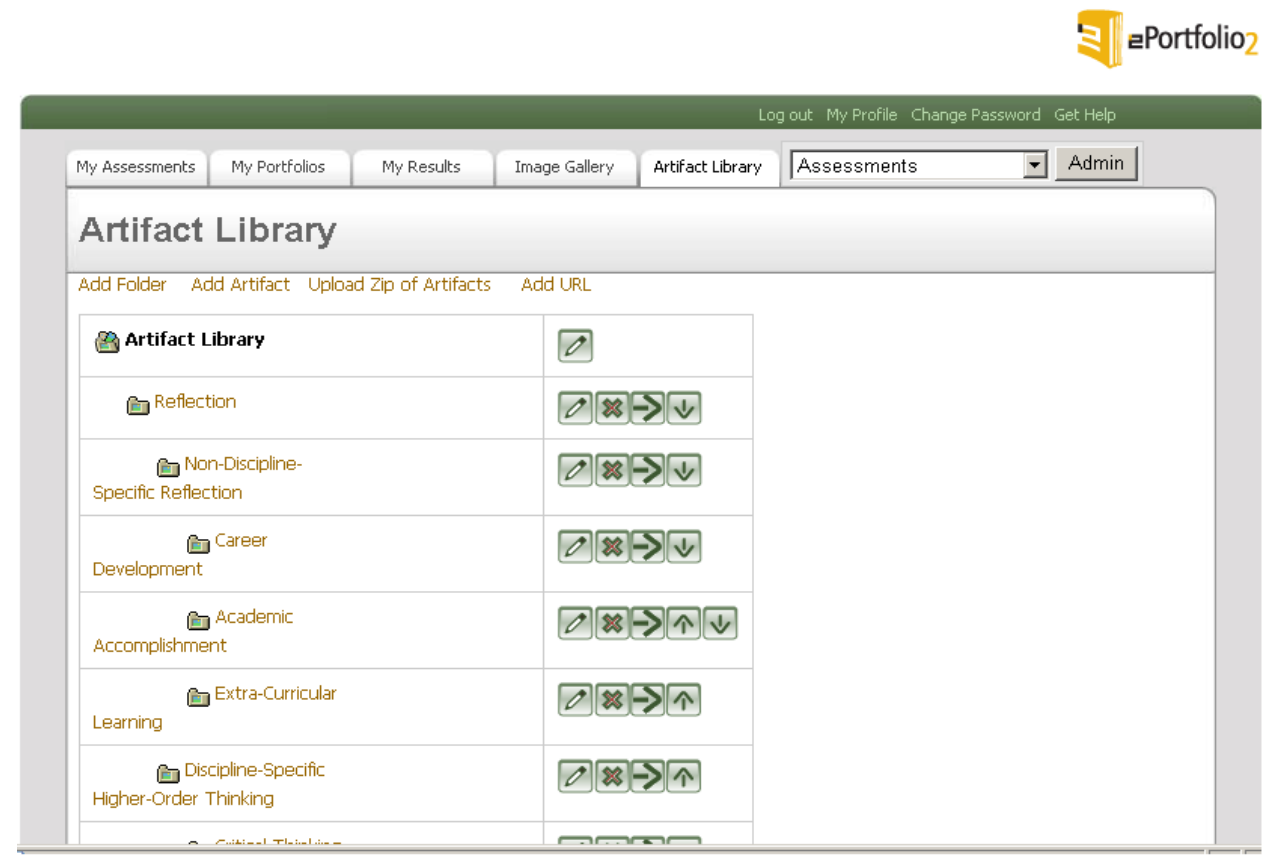

Figure 3: Inquiry-Directed Structure of E-Portfolio Artifacts.

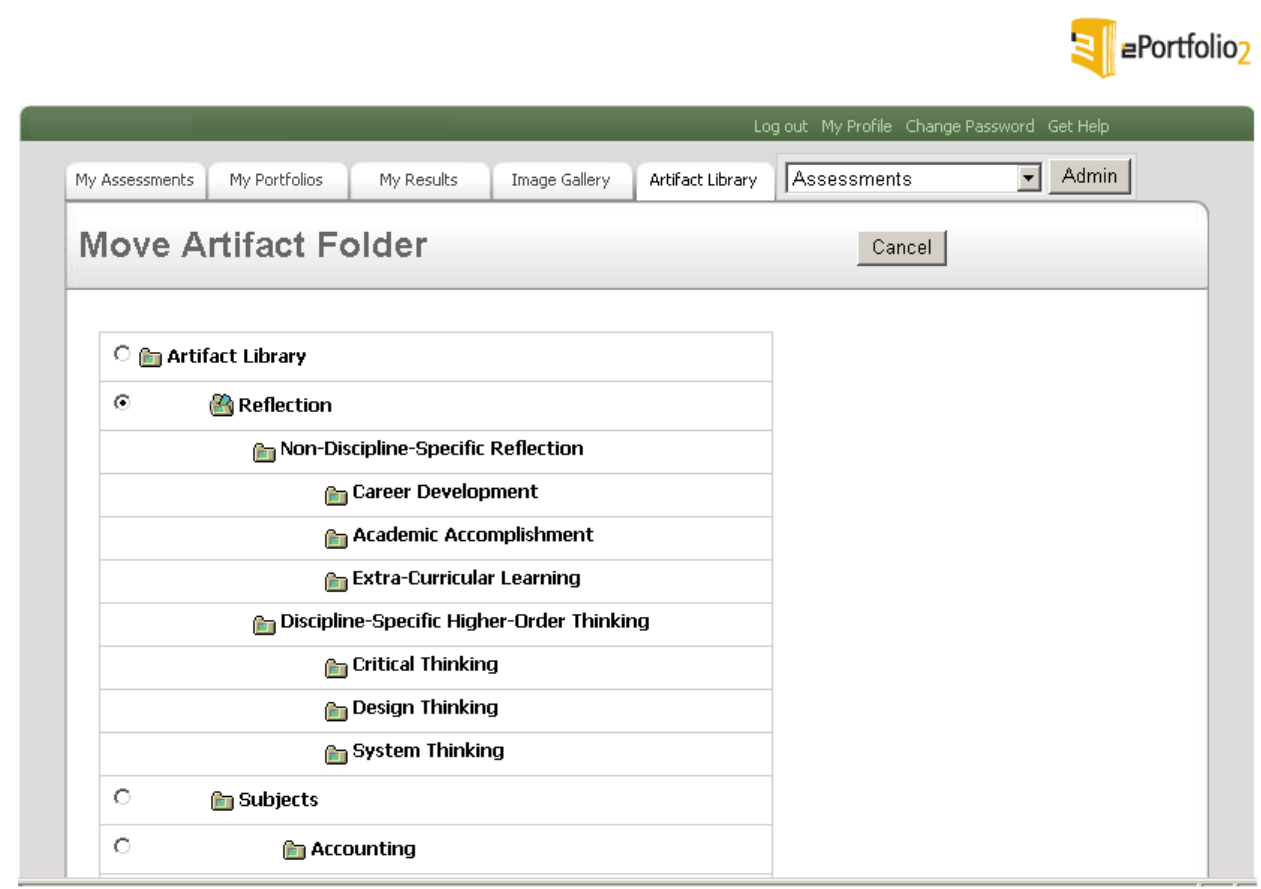

Figure 4: Edit and Update Inquiry-Directed Structure. 


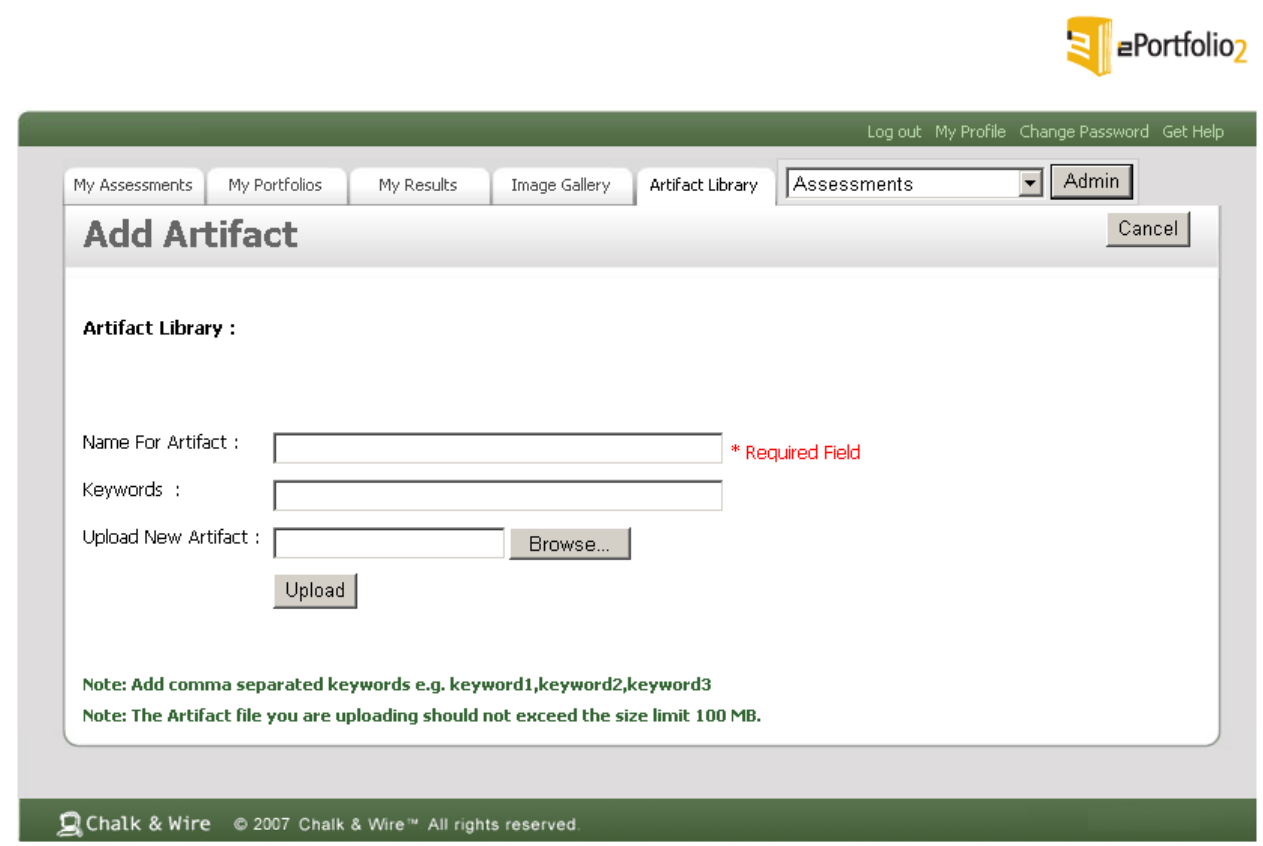

Figure 5: Define Keywords as Semantic Metadata for Reflection.

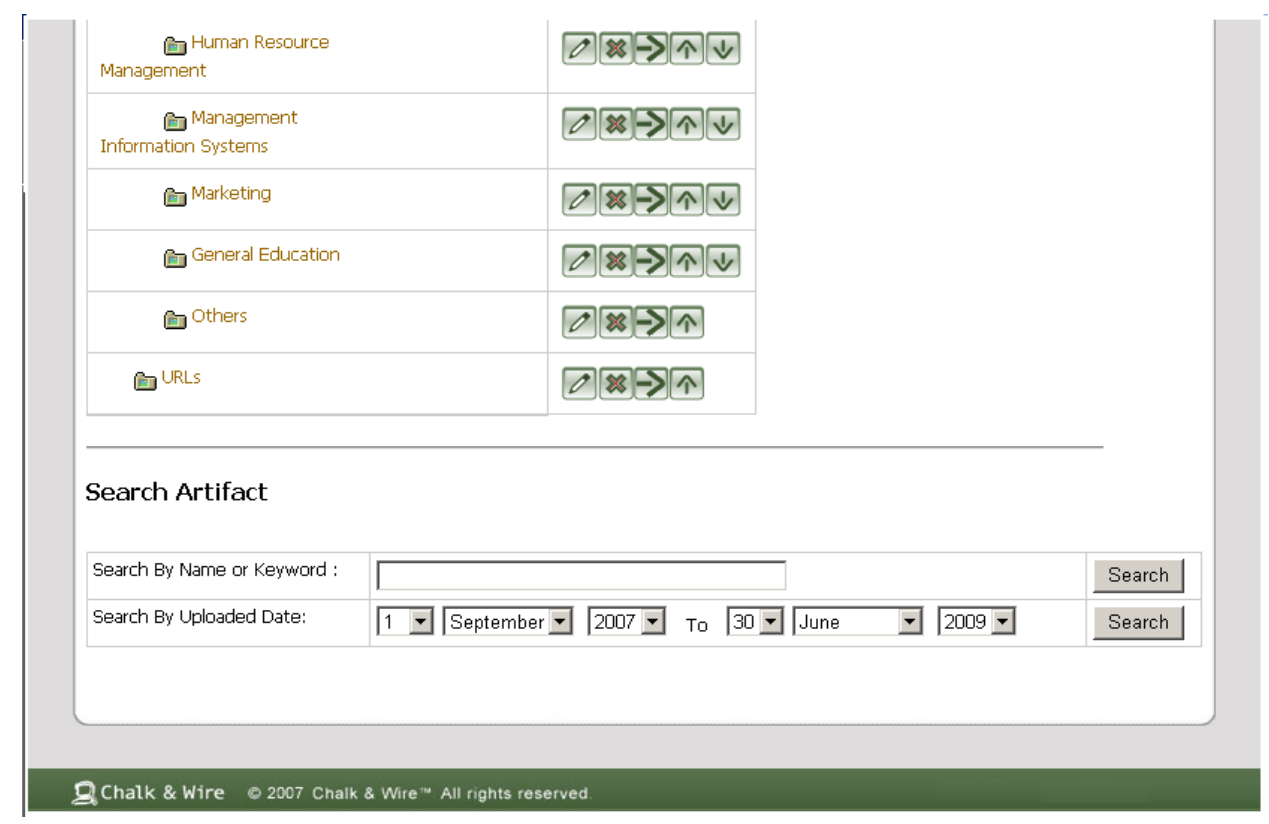

Figure 6: Search Artifacts for Reflection Using Semantic Metadata. 
Our design process clearly demonstrates that the inquiry-directed organization of e-portfolios is derived from the reflection procedural models, dominant models, and reflection inquiries. We believe that, to construct organizations of learning objects for planned teaching and learning, domain knowledge is indispensable.

\section{Discussion on Evaluation}

To verify the effectiveness and the usefulness of this model of inquiry-directed organization of eportfolios, rigorous experiments must be conducted. Preferably, to reduce biases, test experiments should be carried out by researchers who are independent of the designer. This study has its limitation in that the proposed model and the prototype have not reached practical trials beyond the design experience. While it makes no claim to the validity of the proposed approach, this study is carefully based on the literature of reflection and e-portfolios and does offer original ideas of construction of inquiry-directed organization of e-portfolios for teaching and learning integrated reflection. To make an initial contribution to the accumulated weight of empirical evidence for establishing the validity of this model, we discuss advantages and disadvantages of the approach, limitations and potential problems of the model, implications for teaching and learning of the study, and candidate criteria for further evaluation.

\section{Advantages and Disadvantages}

The proposed model of inquiry-directed organization of e-portfolio artifacts is an extension of the existing ontological model of e-portfolios in the aspect of construction of e-portfolio structures. The model is based on the literature of reflection and portfolios. It shows how reflection can be taught and learned from e-portfolios. This model is generic and can be readily implemented on existing e-portfolio systems, although an individual e-portfolio system has its own way of implementation, as demonstrated in our case study. On the weakness side, this model might overemphasize the structure of reflection and, thus, might exclude variant versions of ill-structured reflection.

\section{Limitations and Potential Problems}

This model adds an additional layer between the user and the depository of e-portfolio artifacts. This layer is a shell; that is, the user ought to provide the needed components for the layer. To apply this model, the teacher has to develop relevant reflection inquiries as well as semantic metadata. In fact, the more systematically the semantic metadata and the reflection inquiries are developed, the more useful the e-portfolios would be for reflection. Furthermore, to use the layer, one must connect an e-portfolio artifact to the inquiries. These tedious jobs could be a potential obstacle that interrupts the use of this model.

\section{Implications for Teaching and Learning}

In our view, the major difference between e-portfolios and online course-based learning systems is that e-portfolios shall be the source for the development of life-long learning ability across the dimensions of time, courses, disciplines, and situations. This model provides an environment for students to view their portfolios online for directed reflective thinking and to learn what they have learned. On the teaching side, reflection dominant models and reflection inquiries are high-level information and codified knowledge of teaching reflection and can be shared by the teaching community. This study has shown that e-portfolios can be an integrated reflection tool which has not yet been widely implemented in the e-portfolios community. 


\section{Criteria for Evaluation of the Model}

The effectiveness of reflection is the key criterion for evaluation of the proposed model. However, it is difficult to find a feasible objective measure of the effectiveness of reflection because reflection involves complicated human brain activities. Accordingly, we recommend the following subjective measures for evaluation of the proposed model:

- Comparison of the quality of reflection reports that are written by two contrast groups of learners (i.e., one group uses the proposed model and the other does not use it) and are assessed by the teachers.

- Ratings and opinions of teachers on the usefulness of the model for teaching reflection.

- Ratings and opinions of learners on the usefulness of the model for learning reflection.

- Ratings and opinions of administrators of academic programs on the usefulness of the model.

\section{Conclusion}

The competence of learning objects depends not only on the abundance of artifacts, but also on the accessibility of learning objects for learning. This paper describes how domain knowledge can be used to develop organizational structure of learning objects to support designed teaching and learning. The study recognizes a lack of applications of e-portfolios for integrated reflection beyond course-based assessment and proposes a model of inquiry-directed organization of eportfolios for integrated reflection. This model is based the commonly recognized premise that learning portfolios can be useful for integrated reflection. The model places the focal point on reflection models and reflection inquiry that have not been fully explored in the e-portfolio applications. The model expresses explicit relationships between the e-portfolio artifacts and reflection inquiries to make integrated reflection more visible and more teachable. The inquirydirected organization of e-portfolios can be a teacher's teaching tool for teaching integrated reflection as well as a student's learning tool for self-reflection. Technically, the organization is composed of inquiry structures and semantic metadata of e-portfolio artifacts that are used for reflection.

As an example, we have implemented the model on the Chalk \& Wire ePortfolio2 system. Our preliminary case study has shown new challenges for all parties involved in the e-portfolio community. For educational institutions, there is an organizational need to develop reflection dominant models and reflection inquiries about integrated reflection in various disciplines. The reflection dominant models and reflection inquiries should be maintainable to represent the currency of integrated reflection. For e-portfolio systems developers, new techniques and tools are imperative to develop comprehensive uses of e-portfolios beyond assessment and showcase. In our view, the inquiry-directed model proposed in this study can be used practically for e-portfolio systems development. For teachers, new skills of teaching integrated reflection are required. They must clearly understand the task of teaching integrated reflection and be able to transform unstructured reflection activities to structured procedures through their own reflection inquiries of integrated reflection. For students, applications of e-portfolios for integrated reflection will be a new challenge of e-learning. They must develop new skills to use e-portfolios for self-reflection beyond showcase presentation and passive assessment. In the long run, e-portfolios will be indisputable effective tool for integrated reflection. 


\section{Acknowledgement}

This study was supported by the CWScholars Grant Program of Chalk \& Wire Learning Assessment, Inc. Special thanks to Mr. Geoff Irvine and Ms. Gigi Devanney for their enthusiastic support. The valuable comments of the Editor and anonymous reviewers have contributed to the revision of the article.

\section{References}

Ali, A. I. (2008). Designing digital portfolios for technology support students. Issues in Informing Science and Information Technology, 5, 409-422. Retrieved from http://proceedings.informingscience.org/InSITE2008/IISITv5p409-422Ali502.pdf

Annis (Ferrill), L., \& Jones, C. (1995). Student portfolios: Their objectives, development, and use. In P. Seldin \& Associates, Improving college teaching (pp.181-190). Boston, MA: Anker.

Aram, E. N., \& Noble, D. (1999). Educating prospective managers in the complexity of organizational life. Management Learning, 30(3), 321-342.

Barrett, H. C. (1994). Technology-supported assessment portfolios. The Computing Teacher, 21, 9-12.

Batterbee, L., \& Dunham, A. (2004). Four years of reflection: The digital portfolio project at Albion College. In J. Zubizarreta, (Ed.), The learning portfolio: Reflective practice for improving student learning (pp.59-63). San Francisco, CA: Jossey-Bass.

Boud, D., Keogh, R., \& Walker, D. (Eds.) (1985). Reflection: Turning experience into learning. London, UK: Kogan Page.

Bruder, I. (1993). Alternative assessment: Putting technology to the test. Electronic Learning, 12, 12-28.

Bushweller, K. (1995). The high-tech portfolio. The Executive Educator, 17, 19-22.

Chalk \& Wire. (2009). Chalk \& Wire's ePortfolio authoring, assessment system and data analysis tools. Retrieved August 14, 2009 from http://www.chalkandwire.com/eportfolio

Checkland, P. (1981). Systems thinking, systems practice. New York, NY: Wiley.

Cohen, E., \& Nycz, M. (2006). Learning objects e-learning: An informing science perspective. Interdisciplinary Journal of E-Learning and Learning Objects, 2, 23-24. Retrieved August 24, 2009, from http://www.ijello.org/Volume2/v2p023-034Cohen32.pdf

Collis, B., \& Strijker, A. (2003). Re-usable learning objects in context. International Journal on ELearning, 2(4), 5-16.

Dewey, J. (1933). How we think: A restatement of the relation of reflective thinking to the educative process. Lexington, MA: Heath.

Drier, H. N. (1997). Career portfolios - don't leave home without one. Career Planning \& Adult Development Journal, 12(4), 55-60.

Dublin Core. (2009). Dublin Core Metadata Initiative. Retrieved August 18, 2009 from http://dublincore.org

Dunne, D., \& Martin, R. (2006). Design thinking and how it will change management education: An interview and discussion. Academy of Management Learning \& Education, 5(4), 512-523.

Ericsson, K. A., \& Smith, J. (1991). Toward a general theory of expertise: Prospects and limits. Cambridge, UK: Cambridge University Press.

Fisher, A. (2001). Critical thinking: An introduction. Cambridge, UK: Press Syndicate of the University of Cambridge. Retrieved August 14, 2009 from http://assets.cambridge.org/052100/9847/sample/0521009847ws.pdf

foliotek. (2009). foliotek e-portfolio system. Retrieved August 15, 2009 from http://www.foliotek.com/ . 
Gibbs, G. (1988). Learning by doing: A guide to teaching and learning methods. Oxford, UK: Oxford Polytechnic Further Education Unit.

Greenberg, G. (2004). The digital convergence: Extending the portfolio. Educause Review, 39(4), 28-36.

Guskin, A. (1994). Reducing student costs and enhancing student learning: Restructuring the rule of faculty. Change, 26(5), 16-25.

Harman, K., \& Koohang, A. (2005). Discussion board: A learning object. Interdisciplinary Journal of ELearning and Learning Objects, 1, 67-77. Retrieved August 24, 2009, from http://www.ijello.org/Volume1/v1p067-077Harman.pdf

Huitt, W. (1998). Critical thinking: An overview. Educational Psychology Interactive. Valdosta, GA: Valdosta State University, Retrieved August 23, 2009 from http://chiron.valdosta.edu/whuitt/col/cogsys/critthnk.html

IEEE LTSC. (2009). IEEE Learning Technology Standards Committee. Retrieved August 15, 2009 from http://ieeeltsc.org

IMS. (2006). IMS Meta-data best practice guide for IEE 1484.12.1-2002 standard for learning object metadata version 1.3 final specification. Retrieved August 13, 2009, from http://www.imsproject.org/metadata/

KEEP. (2009). KEEP toolkit. Retrieved August 15, 2009 from http://www.cfkeep.org/static/index.html

Kolb, D. A. (1984). Experiential learning: Experience as the source of learning and development. NJ: Prentice Hall.

Koohang, A. (2004). Creating learning objects in collaborative e-learning settings. Issues in Information Systems, 4(2), 584-590.

Koohang, A., Riley, L., Smith, T., \& Schreurs, J. (2009). E-learning and constructivism: From theory to application. Interdisciplinary Journal of E-Learning and Learning Objects, 5, 91-109. Retrieved August 24, 2009, from http://www.ijello.org/Volume5/IJELLOv5p091-109Koohang655.pdf

Lumsden, J. A., Garis, J. W., Reardon, R. C., Unger, M. P., \& Arkin, S. (2001). A blueprint for building an online career portfolio. Journal of Career Planning and Employment, 62(1), 33-38.

McCowan, C., Harper, W., \& Hauville, K. (2005). Student e-portfolio: The successful implementation of an e-portfolio across a major Australian university. Australian Journal of Career Development, 14(2), 40-52.

Mustaro, P. N., \& Silveira, I. F. (2006). Learning objects: Adaptive retrieval through learning styles. Interdisciplinary Journal of E-Learning and Learning Objects, 2, 35-46. Retrieved August 24, 2009, from http://www.ijello.org/Volume2/v2p035-046Mustaro.pdf

Namuth, D., Fritz, S., King, J., \& Boren, A. (2005). Principles of sustainable learning object libraries. Interdisciplinary Journal of E-Learning and Learning Objects, 1, 181-196. Retrieved August 24, 2009, from http://www.ijello.org/Volume1/v1p181-196Namuth.pdf

Open-Source Portfolio. (2005). White paper: Understanding OSP. Retrieved August 15, 2009 from http://www.rsmart.com/assets/understandingOSP_Dec2005.pdf

Paul, R. W. (1985). Critical thinking research: A response to Stephen Norris. Educational Leadership, $42(8), 46$.

Perkins, D., Jay, E., \& Tishman, S. (1993a). Introduction: New conceptions of thinking. Educational Psychologist, 28(1), 1-5.

Perkins, D., Jay, E., \& Tishman, S. (1993b). New conceptions of thinking: From ontology to education. Educational Psychologist, 28(1), 67-85.

Ritchhart, R. (2002). Intellectual character: What it is, why it matters, and how to get it. San Francisco, CA: Jossey Bass. 
Schon, D. A. (1983). The reflective practitioner. New York: Basic Book.

Senge, P. M. (1990). The fifth discipline: The art and practice of the learning organization. New York: Currency Doubleday.

Sicilia, M. A., \& Lytras, M. (2005). On the representation of change according to different ontologies of learning. International Journal of Learning and Change, 1(1), 66-79.

Simon, H. A. (1976). Administrative behavior (3rd ed.). New York: The Free Press.

Singh, G., Hawkins, L., \& Whymark, G. (2007). An integrated model of collaborative knowledge building. Interdisciplinary Journal of E-Learning and Learning Objects, 3, 85-105. Retrieved August 24, 2009, from http://www.ijello.org/Volume3/IJKLOv3p085-105Singh385.pdf

Smrz, P. (2004). Integrating ontologies into learning management systems - A case of Czech. In R. Meersman, Z. Tari \& A. Corsaro, OTM Workshops, LNCS 3292, pp. 768-772. Berlin: Springer. Retrieved August 20, 2009 from http://www.springerlink.com/index/PG6PQAGL390PRY3T.pdf

Snae, C., \& Brueckner, M. (2007). Ontology-driven e-learning system based on roles and activities for Thai learning environment. Interdisciplinary Journal of E-Learning and Learning Objects, 3, 1-17. Retrieved August 24, 2009, from http://www.ijello.org/Volume3/IJKLOv3p001-017Snae.pdf

TaskStream. (2009). TaskStream e-portfolio system. Retrieved August 18, 2009 from https://www.taskstream.com/pub/

Varner, D., \& Peck, S. R. (2003). Learning from learning journals: The benefits and challenges of using learning journal assignments. Journal of Management Education, 27(1), 52-77.

Wall, K., Higgins, S., Miller, J., \& Packard, N. (2006). Developing digital portfolios: Investigating how digital portfolios can facilitate pupil talk about learning. Technology, Pedagogy and Education, 15(3), 261-273.

Wang, S. (2008). Ontology of learning objects repository for educational knowledge sharing. Interdisciplinary Journal of E-Learning and Learning Objects, 4, 1-12. Retrieved August 24, 2009, from http://www.ijello.org/Volume4/IJELLOv4p001-012Wang200.pdf

Wang, S. (2009). E-portfolios for integrated reflection. Issues in Informing Science and Information Technology, 6, 449-460. Retrieved from http://iisit.org/Vol6/IISITv6p449-460Wang630.pdf

Warnick, B., \& Inch, E. S. (1994), Critical thinking and communication (2nd ed.). New York: Macmillan.

Wiley, D. A., \& Edwards, E. K. (2002). Online self-organizing social systems: The decentralized future of online learning. Quarterly Review of Distance Education, 3(1), 33-46.

Zhang, S. X., Olfman, L., \& Rectham, P. (2007). Designing eportfolio 2.0: Integrating and coordinating web 2.0 services with eportfolio systems for enhancing users' learning. Journal of Information Systems Education, 18(2), 203-214.

Zouaq, A., Nkambou, R., \& Frasson, C. (2007). An integrated approach for automatic aggregation of learning knowledge objects. Interdisciplinary Journal of E-Learning and Learning Objects, 3, 135162. Retrieved August 24, 2009, from http://www.ijello.org/Volume3/IJKLOv3p135-162Zouaq.pdf

Zubizarreta, J. (2004). The learning portfolio: Reflective practice for improving student learning. San Francisco, CA: Jossey-Bass. 


\section{Biography}

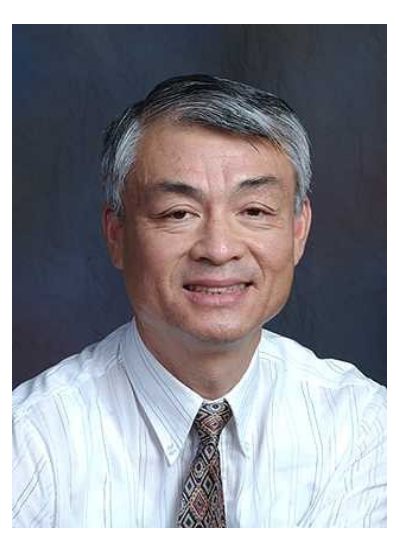

Shouhong Wang is a Professor of MIS in the Department of Decision and Information Sciences at University of Massachusetts Dartmouth. He received his Ph.D. in Information Systems from McMaster University, Canada. His research interests include e-portfolios and learning objects repository design. He has published over 90 papers in academic journals, including Journal of Information Technology Education, Interdisciplinary Journal of Knowledge and Learning Objects, Issues in Informing Science and Information Technology, Journal of Management Information Systems, Information \& Management, International Journal of Information Management, IEEE Transactions on Systems, Man, and Cybernetics, Management Science, Decision Sciences, OMEGA, INFORMS Journal on Computing, Information Resources Management Journal, Knowledge and Information Systems, Journal of Organizational and End User Computing, Journal of Electronic Commerce in Organizations, Journal of Information Technology Management, and others. 